\title{
Blockchain and real estate: Dopo di Noi project
}

\begin{abstract}
Purpose - This paper aims at investigating the possibility of effectively implementing the blockchain technology in the real estate environment, specifically applied to the Trust legal instrument in Dopo di Noi (After Us) project, which is intended to guarantee assistance to persons with severe disabilities.

Design/methodology/approach - The paper is focused on how to apply the blockchain to the tool of Trust, analyzing the main features and characteristics of this technology.

Findings - The paper proposes two potential solutions for managing the Trust tool in the real estate sector, specifically within the Dopo di Noi project. The first simpler proposal is based on timestamping application. The second one radically changes the classical Trust model and introduces an automatization level in the process.

Social implications - The paper presents potential applications of the blockchain technology within the framework of Dopo di Noi project, which allows among other features, legal and tax facilitation for the institution of Trusts to benefit persons with severe disabilities.

Originality/value - This paper highlights the potentiality of the combination of the blockchain technology and the real estate environment and applies the blockchain technology to the Dopo di Noi project. Specifically, with the second solution, the paper proposes a platform that gathers, in a single network, various elements of the blockchain technology, such as timestamping, smart property, smart contract, and links them in order to provide services to persons with severe disabilities.
\end{abstract}

Keywords Blockchain, Real estate, Dopo di Noi, After us, Valorisation, Trust instrument

Paper type Research paper

\section{Introduction}

Since the release of the seminal Bitcoin white paper (Nakamoto, 2018), there has been a growing interest about the blockchain technology, the layer which underlies cryptocurrencies. Like Internet was initially misjudged by main corporations in 1994, blockchain has been treated in the same way by the main institutions and banks until about two years ago, considered as the "bank system's nightmare" (Panetta, 2017).

Because the only reliable and daily-used application of blockchain until some years ago was Bitcoin, this technology was just seen like suspicious and dangerous, without seeing the real potentialities.

In fact, it could be implemented in several fields, and it is considered to be a possible game changer for the future.

The major tool that depicts how the expectations deriving from the blockchain technology have evolved over time is the Gartner's Hype Cycle for Emerging Technologies (Figure 1). As it can be noticed, after the initial hype, which brought the blockchain to the apex of expectations, it is now in the decreasing phase. This proves that the development of real applications based on this technology is still in its infancy period, and it will need more time,

(C) Marzia Morena, Tommaso Truppi, Angela Silvia Pavesi, Genny Cia, Jacopo Giannelli and Marco Tavoni. Published by Emerald Publishing Limited. This article is published under the Creative Commons Attribution (CCBY 4.0) licence. Anyone may reproduce, distribute, translate and create derivative works of this article (for both commercial and non-commercial purposes), subject to full attribution to the original publication and authors. The full terms of this licence may be seen at http://creativecommons.org/licences/ by/4.0/legalcode
Received 28 January 2019

Revised 3 June 2019

9 September 2019

6 November 2019

Accepted 19 December 2019 
PM

38,2

\section{4}

from 5 to 10 years according to Gartner's chart, to be widely spread as trustworthy and efficient in different sectors.

In this general context, the aim of the paper is to analyze the blockchain technology and to evaluate how to implement it into the real estate environment.

Particularly, the core of the paper is focused on how to apply the blockchain to the real estate tool of Trust: more specifically the paper proposes two different solutions to be applied to the project Dopo di noi (After Us) of Lombardy Region in Italy, which uses the legal instrument of Trust to guarantee assistance to persons with severe disabilities.

\section{Blockchain, trust and "Dopo di Noi" (After Us) project}

Once defined the blockchain technology from a technical point of view and analyzed its diffusion in the world, especially in the real estate environment, the paper considers which could be the best applications and potentialities of the distributed ledger technology (DLT). Focusing on the implementation of a platform concerning real estate transactions, the paper proposes two innovative solutions that could adapt the blockchain to that specific legal arrangement known as Trust. The paper explains why the blockchain could improve it by providing an analysis of the technical features and the linkages between Trust and blockchain. The two blockchain-based platforms could manage the Trust instrument, exploiting the timestamping in the first case and the smart contracts and tokenization of the assets in the second case.

Finally, it presents the implementation and adjustment of such solutions to a practical case study regarding the Italian national project Dopo di Noi (After Us), which, among other things, provides tax and legal benefits for the use of Trust for persons with severe disabilities.

\section{Background and context}

\section{The diffusion of the blockchain technology}

The appeal of blockchain technology has spread all over the world, not only among FinTech start-up developments but also among investors who have started to finance them and the regulators and Central Banks.

The increase in the worldwide investment levels demonstrates that in the last years the interest in this technology has actually arisen, as confirmed by the entry of big players such as Goldman Sachs, Deloitte, JP Morgan, IBM, Intel, Disney and many others. Indeed, about $\$ 1$ billion was invested in technology 2016, compared to only 2 million dollars in 2012 (Ferrari, 2017).

Since any asset, any right or any container of value and information can be inserted in a contract, through the blockchain they can be transformed into a code that can be stored and managed in a distributed ledger. Consequently, the technology could be implemented not

Figure 1.

Gartner's hype cycle of 2017 for emerging technologies (Panetta, 2017)
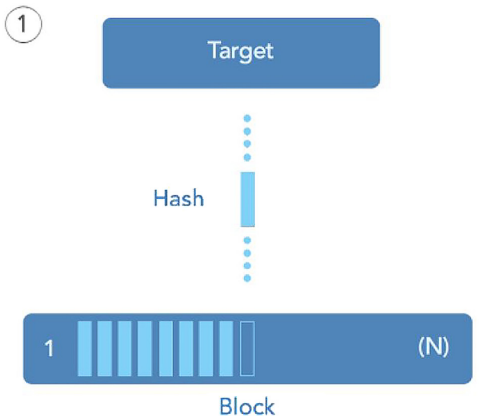

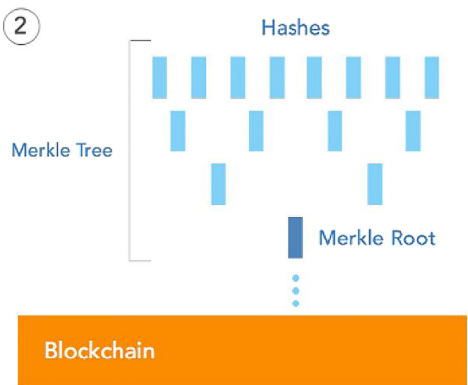


only in the financial world but in general in everything that can record and regulate the Blockchain and ownership of an asset.

Obviously, the first area of application of the blockchain technology concerns monetary transactions. After the creation of Bitcoin, several projects have been developed, which could disrupt in the long term the entire architecture of money transfer (World Economic Forum, 2015).

Nowadays, the main issues against its diffusion are the habit of people to the traditional payment system and the inability of average users to fully understand how the blockchain works and how to create a digital wallet, buy cryptocurrencies and use them.

For these reasons, many innovative start-ups and financial institutions are trying to adapt the blockchain in order to simplify the payment procedure and allow people to easily use it (Fuller, 2017).

Although blockchain technology was perceived as a threat by major financial institutions and banks, they began to analyze it, and once they understood its great potential, they began to test solutions that could adapt to their particular needs. A report by the UK Government Chief Scientific Adviser (UK Government Chief Scientific Adviser, 2016) predicts that the existing infrastructure of the financial system could be gradually replaced in the future by a system consisting of a variety of distributed ledgers linked together on the basis of the blockchain technology. In a recent paper, "The FinTech 2.0 Paper: rebooting financial services" written by Santander InnoVentures with Oliver Wyman and Anthemis group (Santander InnoVentures et al., 2015), it is estimated a cost saving of around $\$ 15-20$ billion per annum by 2022, thanks to the introduction of blockchain technology in the banking sector. Also, the main Italian banks (Intesa Sanpaolo, UniCredit and Banca Mediolanum) together with partners such as Bank of America, Merrill Lynch, HSBC, UBS took part in R3 CEV, an international consortium. R3 CEV, launched in the summer of 2015, aims at building a shared architecture based on blockchain technology focused on serving the financial world.

\section{Blockchain and real estate applications}

Some countries, such as The Netherlands, are starting to develop the first blockchain application in real estate for the purpose of documenting rental contracts (Veuger, 2018). The project comprises:

(1) digitalizing building data;

(2) digitalizing the ownership situation;

(3) transferring ownership;

(4) closing of rental contracts;

(5) unlocking contract information for third parties.

"With the help of Blockchain, we can bring together all information about buildings and give access to parties who need the information. It then works as a kind of building passport" (Veuger, 2018).

Blockchain technology makes it possible to transpose tangible and intangible assets into a digital dimension; in this way, it is possible to record and exchange digitized goods without intermediaries, creating an economy in which trust is not placed in a central authority or in third parties, but it is placed in a complex cryptographic code.

The blockchain is exactly an open register that guarantees itself, without third parties involved.

Furthermore, blockchain can enhance the current transaction process, reducing the time necessary for due diligence and negotiation process and fostering trust between involved parties and reliability of information (Wouda and Opdenakker, 2019). 
Interesting applications for the blockchain could be in the context of the registry and transfer of real estate titles, especially in those legal systems in which the public deeds and the principle of trust in the public authority that deals with real estate registers are ignored or in which a reliable land registry system is absent, as, for instance, in less developed countries.

According to Hernando De Soto, a famous Peruvian economist and antipoverty activist, about 5 billion people do not have proper documentation (Arsenault, 2016). They have difficulty in attesting the management of economic activities, the ownership of their possessions and even certifying their existence. The absence of documentation does not allow them to hold a bank account, denies them the possibility of receiving loans by using their housing as a collateral, denies them the possibility of signing an insurance contract and undermines their contractual status with respect to all those whose lives, properties and commercial activities are legally documented.

Although with some limitations, an implementation of blockchain technology has been proposed for the Honduras land registry system in order to address record-keeping issues faced by the country (Lemieux, 2016).

\section{Challenges and opportunities}

An analysis of the main challenges and related opportunities connected to the purchase/sale or lease of real estate properties (Deloitte, 2018) is reported further:

(1) Presale and prelease due diligence and financial evaluation: in CRE (Commercial Real Estate), previously to leasing or purchase and sale transactions, plenty of time is spent on due diligence activities, in order to assess rental or supply and demand rates. It implies manual verification processes, which increase the time, needed costs and the possibility of errors.

A blockchain-based solution, together with a real estate digital identity system, can expedite some of the pretransaction activities by simply verifying the physical identity related to the digital one, which can contain all the information such as vacancy, tenant profile, financial and legal status.

(2) Leasing and subsequent property and cash flow management: the management of a lease and the related cash flows is really complex, since it involves several actors and several payments, resulting in an expensive and long-lasting process.

The exploitation of a smart tenancy contract instead of traditional real estate lease can simplify and automate the procedure and consequently reduce time and costs for property and cash flow management. Moreover, the lease terms and transactions could be registered on the blockchain ensuring higher transparency, and it would be easier to do automatic payments to real estate owners and property managers or implement a deposit function. Indeed, for instance, the smart contract could manage an initial deposit and automatically give the deposit back once the lease is finished, just holding the amount needed for possible damages.

(3) Decision-making: usually, in the current system, all the databases or processes related to CRE are segregated and information is not uniform and reliable.

The blockchain can increase the interoperability among CRE technology systems and the actors involved in a lease or purchase/sale real estate transaction. Indeed, by providing a shared and transparent database, real-time information can be retrieved in an easier way and can be shared faster among the different stakeholders, which can make better decisions.

(4) Financing and Payments: in CRE money transfer for payments or funding related to property transactions can be very expensive and time-consuming because of the extensive documentation and the several players involved in the process. 
In particular, when the buyer makes the purchase through a mortgage, the time needed and the costs increase considerably.

Blockchain and real estate

The blockchain can improve the financing process by executing a smart contract accessible to the involved parties, which manages the loan application, the documentation and the due diligence, even allowing real-time control of the mortgage. In the case of cross-border transactions, the blockchain can provide a shared transparent ledger, which allows easier transfers reducing risks and payments delay.

\section{Timestamping}

The timestamp, sometimes defined as "proofs of existence" (Todd, 2016), is used to certify the existence of a piece of information in a certain point in time.

Timestamping based on decentralized blockchains with high hashing power such as Bitcoin or Ethereum blockchain has three benefits over the existing alternatives (Todd, 2016):

(1) Trust. It is publicly auditable, eliminating the presence for trusted third parties; it supports notarization methods.

(2) Cost. It scales indefinitely, allowing to create an unlimited number of timestamps into one transaction for free.

(3) Convenience. It can create a third-party-verifiable timestamp in about a second, not needing to wait for a confirmation.

In everyday life, a receipt represents the proof with which buyers demonstrate that they have made a specific transaction. Within the blockchain, the receipt provides all the information necessary to prove the membership of a single hash to the Merkle Tree whose root was published with a transaction in the blockchain.

Drawing a route from the Merkle Root to the destination hash, it is possible to define the Merkle Proof, which shows if the element considered is in the Merkle Tree, without knowing the whole tree.

A blockchain receipt includes the Target Hash, Merkle Proof, Merkle Root and Bitcoin Transaction ID as depicted in Figure 2.

The timestamping appears capable of operating in synergy with the current cadastral system for an even more efficient and secure registration of real estate titles and their transfer (Figure 3).

The entire timestamping process flow is schematized in Figure 4.

Strictly related to land and title registry, the main area of interest for the application of the blockchain technology to the world of real estate concerns the management of the purchase and sale or lease of properties.
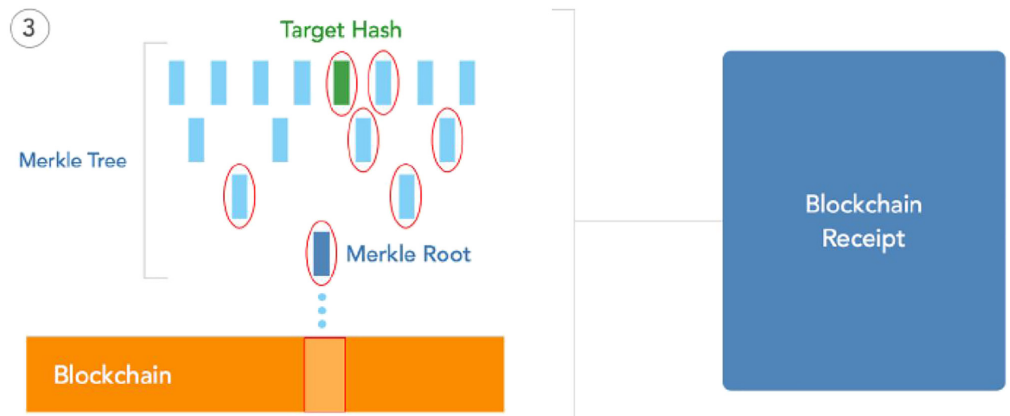

Figure 2.

Recording document in the blockchain

Transaction ID 
PM

38,2

Figure 3.

Blockchain receipt

(Vaughan et al., 2015)
Figure 4.

Timestamping process flow[2]

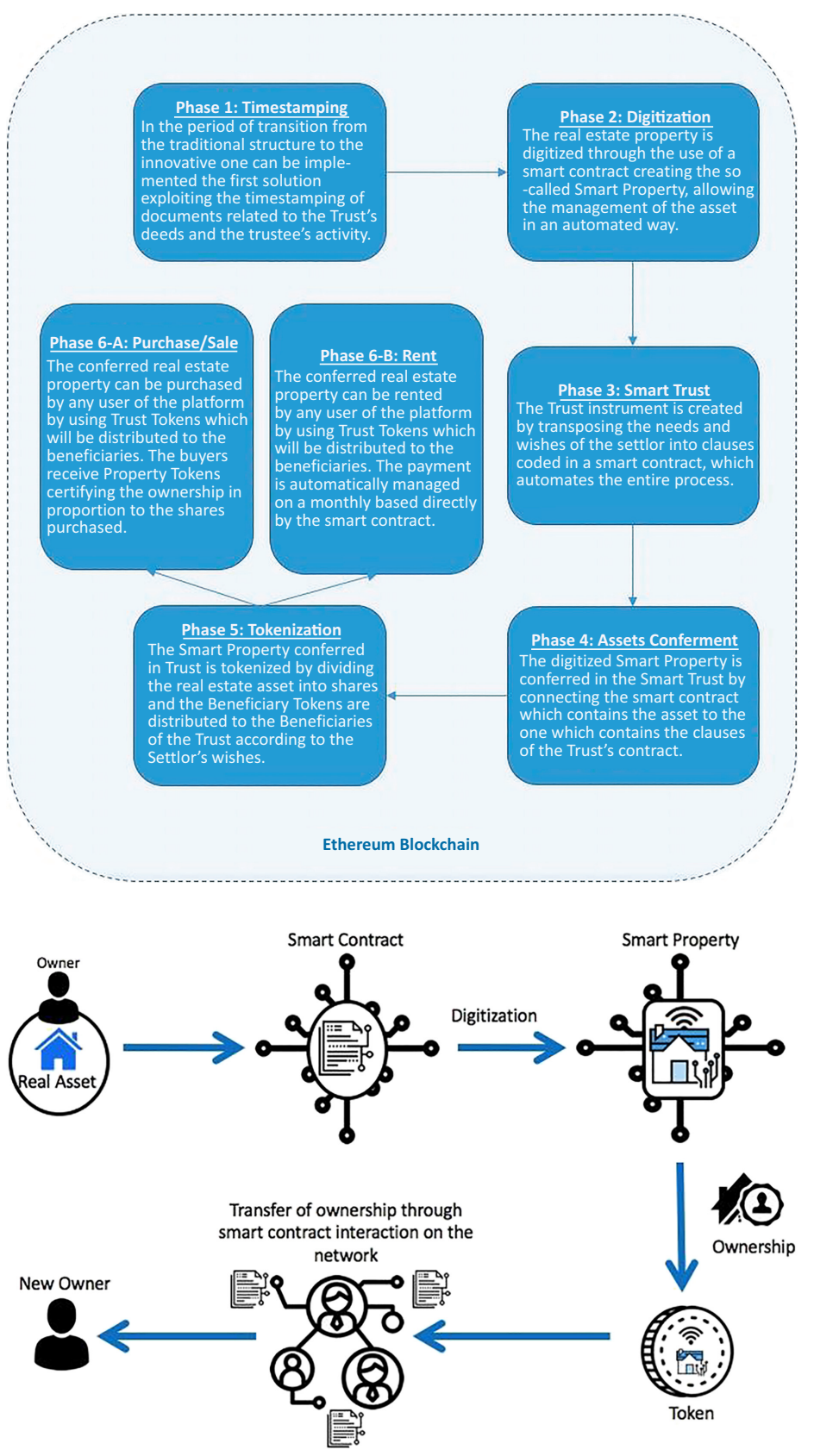

Through the so-called smart contracts, the blockchain is able to manage the entire contract stipulated, evaluate the progression of payments and take immediate actions such as the activation of insurance funds or forced transfer of money in case there are some problems (see Figure 5). 
Blockchain and

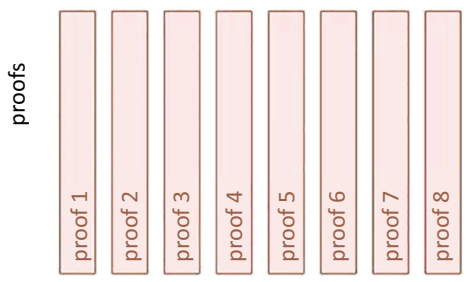

real estate
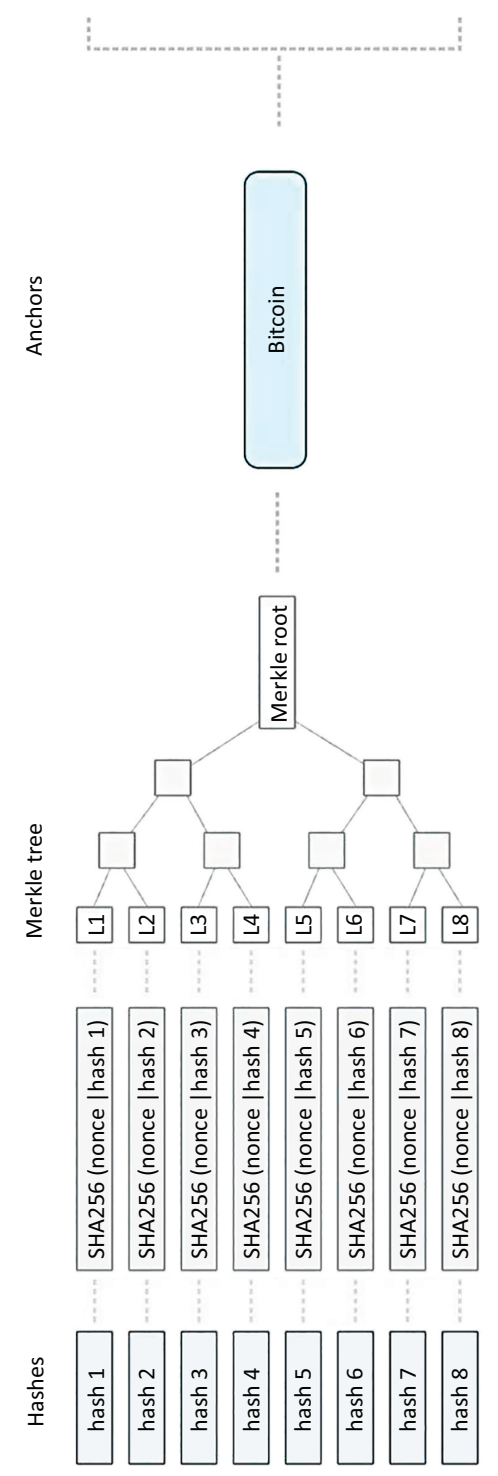

Figure 5. Smart contract functioning for real estate transaction (Liu, 2018) 
PM

38,2

280

\section{Asset tokenization}

The term "tokenization" has its origin in the fields of data security and lexical analysis. Referred to data analysis, it represents the process of replacing sensitive data with unique identification symbols, called tokens, containing all the essential information about the data without compromising its security. A tokenization system, secured and validated using security best practices, allows to create tokens from sensitive data and detokenize tokens back to sensitive data.

Referred to lexical analysis, it represents the process of breaking a string of input characters into words, symbols or phrases called tokens (see Figure 6).

When applied to any type of asset, the tokenization can be seen as a method to convert rights to an asset into a digital token and then trade these tokens on a digital platform. Applied in its turn to the blockchain technology, it means having a real-world asset digitally represented and recorded on an immutable decentralized ledger (Kravchenko, 2017).

\section{Tokenization in the real estate field}

In particular, real estate assets are difficult to physically divide or transfer, but through the blockchain the ownership rights can be converted in digital tokens that are backed by the assets themselves.

Following a crowdfunding model, the asset is not tokenized itself, but it is divided into shares, which in turn are tokenized. So, tokenizing a real estate asset means the generation, through a smart contract, of tokens corresponding to the shares of the real estate asset and the attribution of value to these tokens according to the value of the property (Vidal, 2017).

In general, the implementation of such method would increase liquidity for real estate asset markets, turning the real estate appraisers into "equity analyst," since any building tokens could be treated like stock shares of a company. In this way, through the use of the blockchain, the real estate investments become more appealing.

Moreover, another important benefit deriving from the asset tokenization is security, as digitally trading tokens avoid problems both for buyers and sellers for what concerns physical and operational security (Wolfson, 2017).

\section{Challenges for asset tokenization}

Nowadays the rise of a new technology has to face several challenges such as (McKeon, 2017):

(1) Regulatory: even if the blockchain technology has been partially established in recent years, the tokenization of assets will probably take years or decades to completely

Figure 6.

Real estate asset tokenization scheme[3]
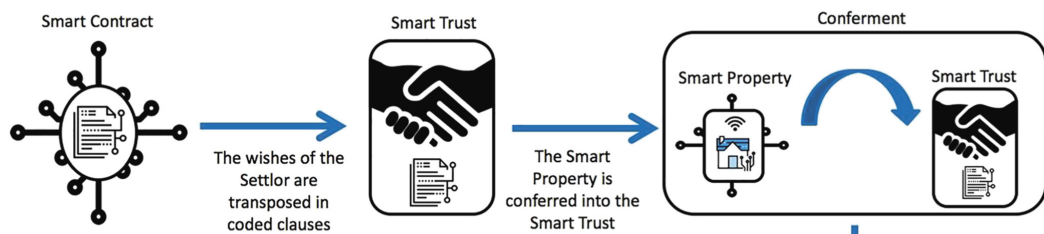

Smart Trust
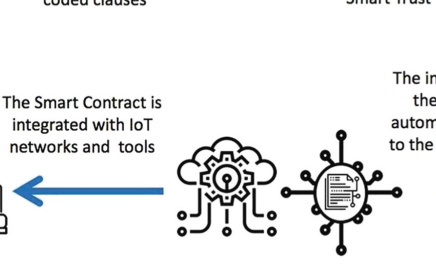

information provided by the oracles triggers the

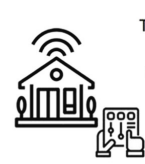

the Smart Contract clauses

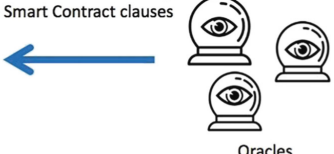


develop. Indeed, as we know from previous endeavors, technology evolves and changes in a fast way, but regulation usually follows a long and slow path to adapt. Asset tokenization will probably represent one of the greatest challenges for global regulatory agencies in the next years.

(2) Liquidity: the creation of tokens corresponding to a real-world asset does not affect directly its liquidity. Indeed, the assumption for an increase in liquidity derives from a greater trading volume and a greater number of participants; if the exchange volume concerning tokens market of an asset is low, the traded asset is still considered relatively illiquid. However, asset tokenization allows to create a deeper market with a potential number of participants significantly higher with respect to the one currently in use.

(3) Governance: the tokenization of a real estate asset leads to the splitting of the asset property. This makes the management of some aspects more difficult like the maintenance monitoring, since each owner may not have incentives due to the higher costs of monitoring with respect to their investment, meaning that a single owner has more incentives to manage the building than 1,000 different token holders. The market should provide some solutions such as a weighed payment for governance services according to the percentage of held tokens.

(4) Status quo: the tokenization of real estate assets will disrupt the current system, which will have to evolve and adapt, but this is made more difficult by some stakeholders that are trying to slow down this change of paradigm due to the higher benefits deriving from the current one.

\section{Dopo di Noi (After Us)}

The Dopo di Noi project is a legislative provision at Italian national level aimed at increasing the benefits and funds that can allow persons with severe disabilities to continue on their life paths, also when the family support ceases to exist.

This project is defined by the Law No. 112 of June 22, 2016 "Disposizioni in materia di assistenza in favore delle persone con disabilità grave prive di sostegno familiar" "Provisions on assistance in favour of persons with severe disabilities without family support"), whose general rules are established by the D.M. November 23, 2016-Decree of the Ministry of Labor and Social Policies (MLPS-Ministero del Lavoro e Politiche Sociali).

\section{Law No. 112/2016}

The expression Dopo di Noi (After Us) has always been simply intended with the need to provide residential facilities with the greatest possible capacity to transfer disabled persons when family support was lacking, either because of the loss of parents or other family members or because of the physical incapacity of the latter.

The Law No. 112/2016 disrupts this concept by providing a much deeper and more human interpretation, which for the first time considers persons with disabilities not as passive human beings whose only need is to be assisted in special structures, but as real persons who cannot, from one day to the next, be "deported" to a structure, sometimes even hundreds of kilometers away from the social fabric where they lived (OpenTimestamps).

This vision is based on the United Nations "Convention on the Rights of Persons with Disabilities" (CRPD) of 2006, ratified by Italy in 2009, which requires to consider these persons not only in relation to their limitations but also as persons who have the right to develop their life path in conditions of equal opportunity with all the others (UN, 2006). 
PM

38,2

282
Beneficiaries and interventions

The D.M. November 23, 2016 envisages life-support measures for the following beneficiaries (Regione Lombardia, 2017):

(1) Persons with severe disabilities (ascertained in accordance with article 3, paragraph 3, Law No. 104/1992);

(2) Without family support.

These support measures are divided into four areas of intervention:

(1) Programs to increase awareness and develop skills for managing daily life activities and achieving the highest possible level of autonomy.

(2) Interventions to support home care services and aimed at facilitating the deinstitutionalization favoring housing solutions that reproduce housing and relational conditions of the family home and that take into account the best opportunities offered by new technologies.

(3) Interventions for the temporary stay in an extrafamiliar housing solution to cope with any emergency situations, respecting, as far as possible, the will of persons with severe disabilities, of their parents or of those who protect their interests.

(4) Interventions for innovative housing solutions that may include the payment of purchase, lease, renovation charges, installation of plant systems and equipment, also supporting forms of mutual aid among disabled persons, with reuse of real estate assets made available by family members of persons with severe disabilities in their favor.

The proposed residential solutions are mainly three (Regione Lombardia, 2017):

(1) Apartment groups: apartment where two to five disabled persons live together such as:

- Community social housing in which the managing organization provides the hotel, educational and assistance services;

- Apartment groups in which a public or private organization provides hotel, educational and assistance services;

- Self-managed apartment groups in which the disabled persons provide themselves with accommodation, educational and assistance services.

(2) Cohousing: housing systems composed of private spaces and spaces for common use and sharing between different co-housers. The manager, in addition to the housing service, can provide disabled persons with services of assistance nature and/or educational/animating nature.

(3) Housing: social housing that reduces the discomfort of disadvantaged persons with disabilities who cannot afford to rent a house in the free market (Zaccaria et al., 2018).

The priority of access is defined on the basis of the presence or absence of parents, their seniority and family economic condition, as well as the consideration of the multidimensional assessment (valutazione multidimensionale) and the individual project (progetto individuale) of the disabled person.

\section{National Fund}

The project is extended to the Italian national level and is financed by a special National Fund, which will be distributed to the regions; each of them, according to the Law No. 112/2016, must propose a regional plan to put into effect the ministerial decree of November 23, 2016. 
The National Fund consists of (Regione Lombardia, 2017):

(1) $€ 90.0$ million for 2016

(2) $€ 38.3$ million for 2017

(3) $€ 56.1$ million from 2018 onward.

Concerning the funds related to 2016, for instance, they have been divided among the various regions as follows:

This subdivision was carried out, considering each single region, on the basis of the number of persons aged between 18 and 64 years with severe disabilities, according to the Law No. 104/92.

This parameter does not limit the benefit of the application of the Law No. 112/2016 exclusively to persons with severe disabilities between 18 and 64 years old, but it has been used to allocate the fund.

\section{Trust for Dopo di Noi (After Us)}

The main link between the Dopo di Noi (After Us) project and platform that will be proposed lies in the fact that the former provides a series of legal, tax and insurance benefits for Trusts made available to parents or relatives of disabled persons, drafted in order to integrate the measures financed by the National Fund.

Normally, the transfer of ownership of a property in case of inheritance or donation for the benefit of a person with severe disabilities (defined by Law No. 104 of 1992) is subject to a facilitated tax treatment. Indeed, it provides that the inheritance or donation tax is applied only on the portion of the inherited (or donated) portion that exceeds the amount of $1,500,000$ euros.

Furthermore, the Law No. 112 of June 22, 2016 provides for the complete exemption from this tax for assets transferred to a Trust or encumbered by a destination tie and for those allocated to special funds set up for persons with severe disabilities.

To understand how to adapt the proposed blockchain-based solution to the application of the Trust tool related to the Dopo di Noi (After Us) project, it is necessary to analyze the main differences in the process and the roles of the different actors compared to the normal case of application.

\section{Trust}

The Trust is an institution of the Anglo-Saxon common law system, which regulates a multiplicity of legal relations of financial nature. Trust is defined as a legal relationship established by a subject, called settlor or grantor, who during her/his life and after her/his death entrusts her/his property to another subject, the trustee, which, with the commitment to administer them, preserves them and makes them profitable in the interest of the beneficiaries identified by the settlor.

It is also possible to appoint a protector whose task is to supervise the activity of the trustee; the usefulness of the protector lies in the fact that often the role of trustee is carried out by bank institutions, which are ideal for the management of wealth, but require an appropriate control in the exercise of the activity of trustee.

In Italy, the trust instrument finds legal legitimacy following the adhesion to The Hague Convention of July 1, 1985, made enforceable since January 1, 1992.

In the case of Dopo di Noi, the main functions of the various participants remain unchanged, but there are differences due to the greater complexity of the situation and the greater number of needs to be met in terms of contractual clauses. 
Settlor. In the case of disabled beneficiaries, the settlor is usually a parent, supported or not by their spouse. The parent knows and understands the real needs of the disabled child and consequently is able to give correct indications and directives to the trustee on the habits of life and particular needs of the weaker subject. In this specific situation, these indications are more important than general directives relating to the management of the property itself, giving prevalence to the persons.

A special case may concern a Trust deed drawn up by the disabled person, who is both a settlor and a beneficiary at the same time; in this case it will be the responsibility of these persons to make sure that the trustee receives all the information necessary for their maintenance when they will no longer be able to manage themselves.

Trustee. The role of the trustee is fundamental: they must be able to manage the real estate assets conferred in the Trust for the benefit of the vulnerable person to be protected, following with care and attention the settlor's directives in order to ensure that all the needs of the person are met.

This role can be played by a natural or legal person, including cooperatives and ONLUS; given this particular case, it can also be done by a lawyer together with the family doctor who is treating the vulnerable person.

In general, the trustee is selected among the persons close to the subject to be protected and often, for simplicity, the task is assumed by the parents.

Indeed, in this case the trustee must not give priority to purely economic logic, but must keep the emotional and social sphere of the vulnerable person in the foreground.

Beneficiaries. The beneficiary is the disabled person who is protected through the establishment of the Trust and the figure of the trustee, who guarantees assistance, care and maintenance of the beneficiary both by paying the revenues deriving from the management of the properties conferred in the Trust and by directly dealing with the person and with her/ his needs.

An important distinction to be made in the case of a Trust applied to the Dopo di Noi is the one between the recipients of the income and the final beneficiaries. The recipients of the income are the recipients of every revenue that derives from the management of the conferred assets, usually the disabled person. The final beneficiaries are the subjects to whom, once the Trust is concluded, the assets constituting the fund are transferred, usually the siblings of the vulnerable person.

Protector. In the event that the beneficiary of the Trust is a person with severe disabilities, the role of the protector (or guardian) becomes fundamental. Indeed, the protector monitors the work of the trustee and guarantees its correctness from a moral point of view, that is, the commitment to guarantee the psychological well-being of the disabled person without taking advantage of this position in order to reach a personal benefit or interest.

In general, the guardian can be a physical person, a legal person, an institution, an association, a company.

\section{The platforms proposals}

First solution: Proof of trust

The first solution is the simpler among the proposed ones and exploits the timestamping application of blockchain technology.

The proposal consists in applying, through the use of timestamping, a sort of digital sign to all the off-chain documentation regarding the stipulation of the Trust's deed and the activity of the trustee in order to make them indelible by recording them on the blockchain.

The "upload" of the documents on the blockchain proves their existence in a specific date and in a specific form, which cannot be altered by anyone, enabling the resolution of possible future disputes. 
This allows the system to rely on a higher level of transparency and security with respect to the traditional structure of the Trust instrument. Furthermore, the protector's duty to control the trustee decision would be facilitated, and the beneficiary would obtain a sort of "history of trustee activity" to verify that the conferred assets have been managed in an appropriate way. This solution can be implemented on both Bitcoin and Ethereum Blockchain because these, due to their uninterrupted functioning and high computational power, are considered "the most trusted" among the blockchains.

Practically, the idea is to exploit the hashing function of the blockchain and create a hash real estate (a sort of coded fingerprint of the document) for each document pertaining to the Trust's contracts and the trustee activity and record these hashes on the blockchain through particular transactions. While the hashes are recorded on the blockchain system, the documentation files are collected and stored in external off-chain databases.

Once each document is hashed, the hashes are collected together in a structured Merkle Tree and the Merkle Tree Root containing all the hashes of all the documents we want to record on the blockchain is obtained.

In order to prove the authenticity of the stored documents in the off-chain database, the protector or the beneficiary can use the hashing procedure to obtain a Merkle Root and compare it with the one calculated in the first place; if they match, it means that there was no tampering and consequently the documentation is reliable.

The solution could be developed by using "Open Timestamps," a standard for timestamping developed by Peter Todd[5].

The workflow of the process is explained and depicted in Figure 7.

\section{Second solution: Smart trust token}

The second solution, more complex both from a technical point of view and as a practical implementation, consists in the development of a Trust estate platform.

The proposal is based on the Ethererum blockchain technology, which allows the development of complex smart contracts, better suited to the needs of this specific application.

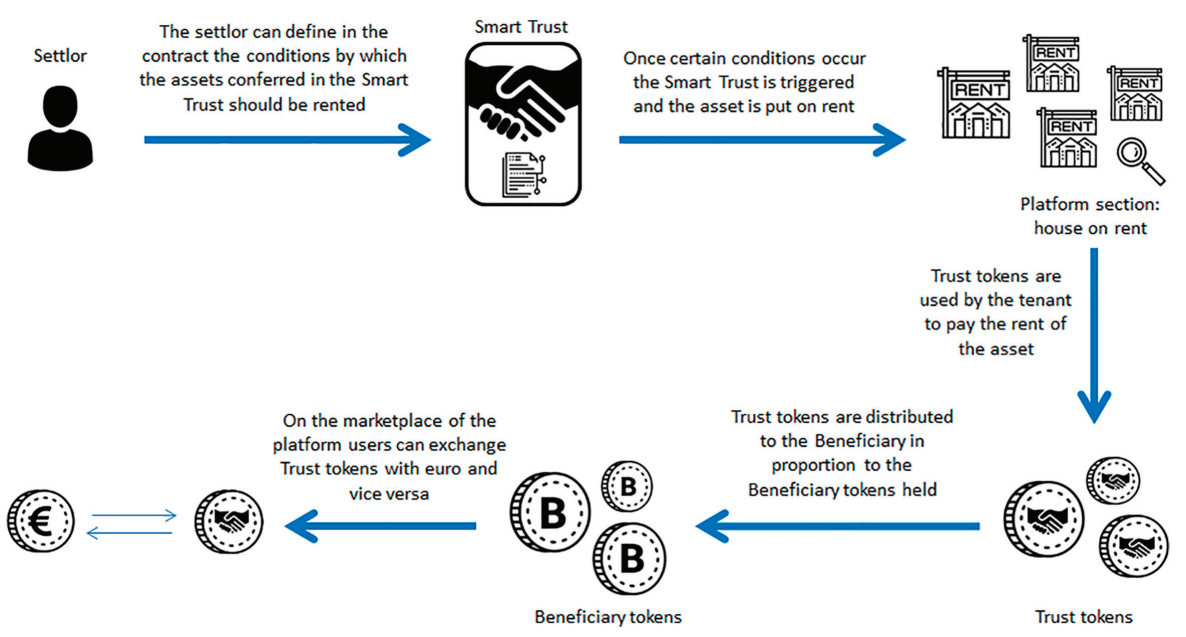

Source(s): authors' elaboration

Figure 7.

Timestamping process for the proof of trust 
PM

38,2

\section{6}

This platform gathers in a single network all the elements analyzed in the previous parts, such as timestamping, smart property, smart contract, tokenization and IoT[1], linking them in order to provide a global service related to the Trust sector applied to real estate.

The future potential developments of the blockchain technology are associated with the ability to integrate different processes and systems in an automated way (Nawari and Ravindran, 2019).

The aim is to create a system to improve efficiency and reduce costs related to the creation and management of the Trust legal instrument and of the assets conferred in it and at the same time increase its security, transparency and resilience.

The different phases of the process are shortly depicted in Figure 8 and better described in the following paragraphs.

Timestamping of the documentation. Theoretically, the timestamping of the documentation relating to the Trust and the conferred assets, in the case of the second solution proposed, would be a redundant and unnecessary operation, as the Trust act containing all the information and clauses is implemented in the code of the smart contract. However, in a first period of transition between the traditional structure and the innovative one proposed on blockchain, a hybrid solution could be adopted that registers the Trust act through both the smart contract and the hashing function exploited and implemented in the less disruptive solution described in the previous paragraph.

Digitization of the property-smart property. The fundamental step toward the realization of a Smart Trust is the digitization of the real estate assets. It consists in the creation of a digital identity of the real estate assets, called Smart Property (see Figure 9).

A property can be sold or transferred through an interaction of the smart contract with other smart contracts or accounts through a transaction. In this way, the management of the building could be automated and takes place in a more immediate way, reducing time and costs.

Creation of smart trust and conferment of an asset. Once the property has been digitized, the interaction between smart property and smart contract allows the creation of a Smart Trust for the management of properties in an automated way; this step would enable to achieve the main objective of the proposed platform, that is, the elimination of intermediaries within the developing process of a traditional Trust and the subsequent reduction in the required time and costs.
Figure 8.

Process flow of the second solution: Trust estate platform

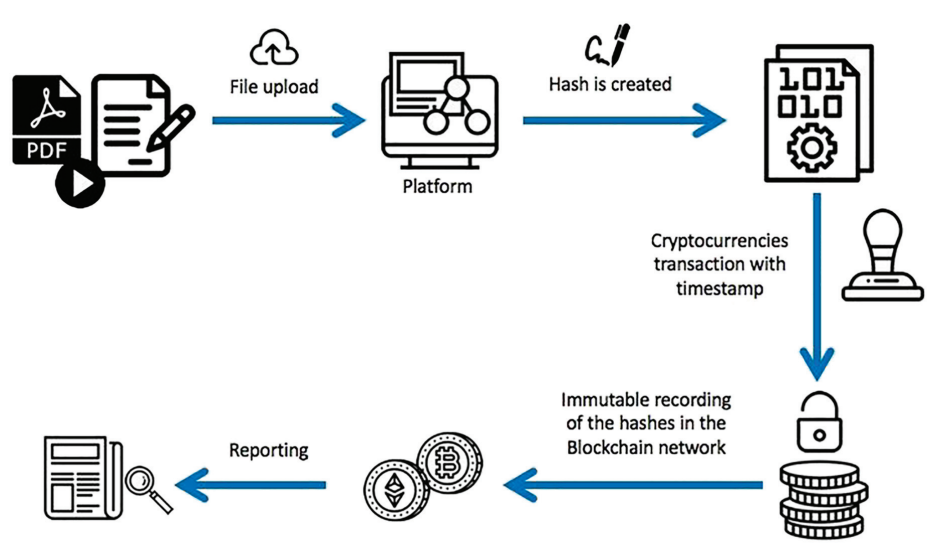

Source(s): authors' elaboration 


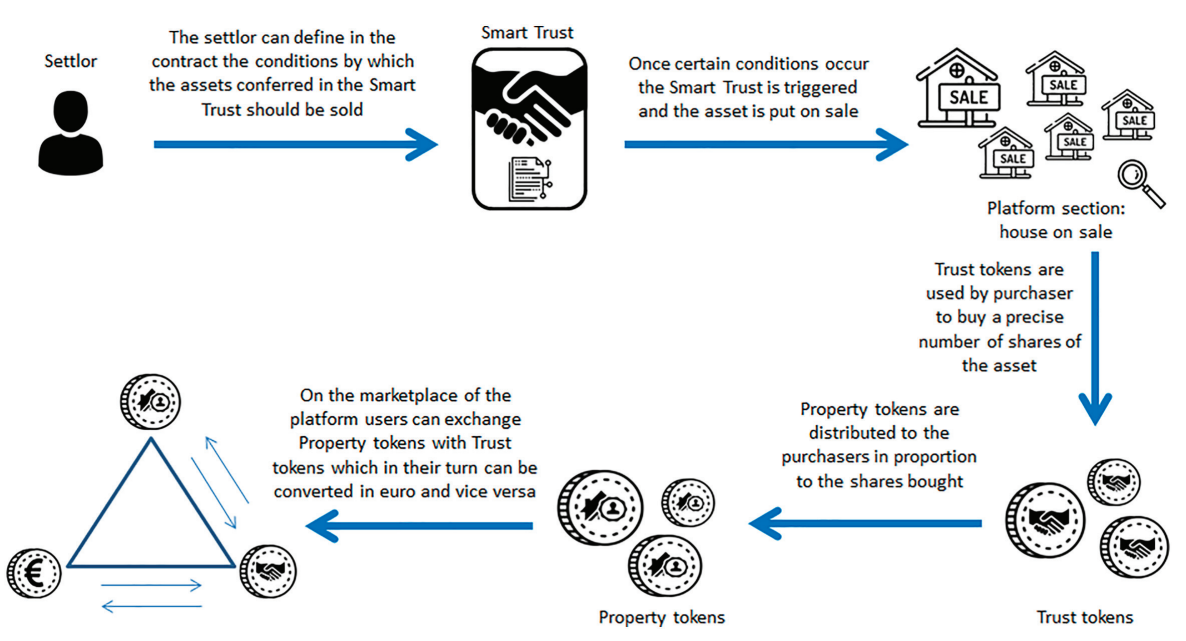

Source(s): authors' elaboration
Blockchain and real estate

287

An important aspect to consider is the concept of ownership in civil law system, which requires the figure of a physical owner; in this case, besides using a typical Common Law tool, the property is entrusted to an entity that is not really tangible and achievable, so the innovation and the change of paradigm are remarkable.

The complexity of this passage consists in transforming all the clauses established by the settlor into a code language in such a way as to provide a solution for any type of eventuality that could occur in the management of the assets conferred in the Trust.

The only external involvement is carried out by the so-called Oracles, agents with the task of communicating the actual occurrence of a certain event or the occurrence of a certain condition in the off-chain world, such as the death of the settlor or of one of the beneficiaries or some natural event that involves maintenance interventions to the assigned assets.

The role of Oracles is made necessary by the creation of a virtual environment of smart contract and smart property that connects real estate assets to the world of blockchain without an automatic information flow exchange. By connecting two different realities, this connection node could undermine the concept of decentralization and automation of the blockchain-based Trust tool: this problem can be partially solved by a series of measures.

First of all, in order to avoid placing the entire trust in a single Oracle and thus to avoid a single point of failure or any corruption, a pool of Oracles could be adopted to cross information from different sources and increase the level of accuracy, also enhanced by a feedback system to evaluate the reliability of different Oracles.

Furthermore, the simple verification of the disappearance of the settlor or of one of the beneficiaries could be carried out by means of a digital signature with a private key by the same at regular time intervals (see Figure 10).

Tokenization of assets and market place. Once the Smart Trust has been created and the assets have been assigned to the smart contract, tokenization will be exploited.

Several types of Tokens are presented further, each one with a different purpose, which allows the operations on the platform and the provision of the various services offered.

(1) Trust tokens: these are the main tokens that allow to operate within the platform and can be used to interact with other users and benefit from the services. 
PM

38,2

\section{8}

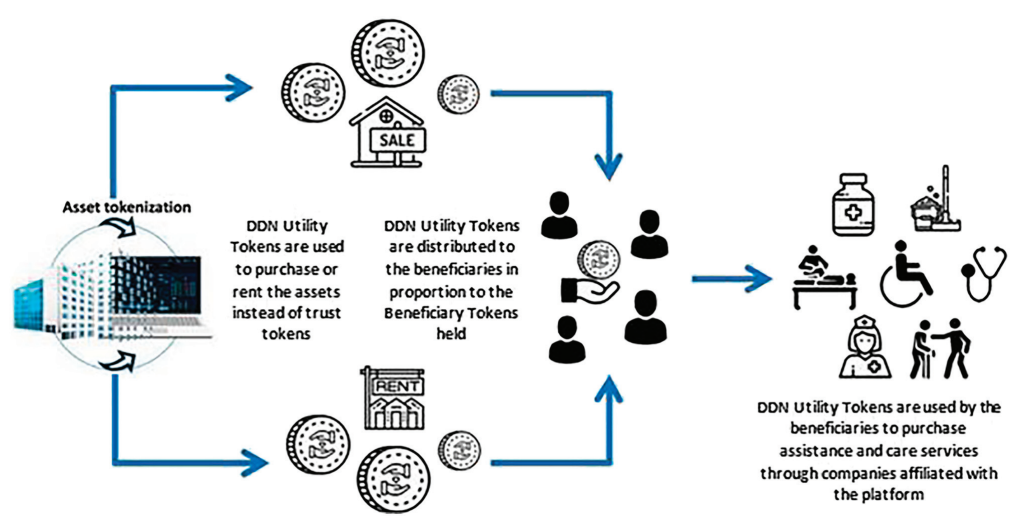

Figure 10.

Process flow of smart trust creation and assets conferment

Figure 11.

Process flow of asset tokenization and tokens generation
Source(s): authors' elaboration

(2) Beneficiary tokens: these tokens attribute and identify the "beneficiary status" of the Trust. They are automatically distributed by the smart contract, according to the conditions imposed in the code, when the Smart Trust is created according to the settlor's guidelines.

(3) Property tokens: these tokens attribute and identify the ownership of a part of a real estate property that is decomposed into units, just as it happens in the securitization process.

They are assigned to each buyer of the property based on the percentage of the property purchased using the Trust Tokens (see Figure 11).

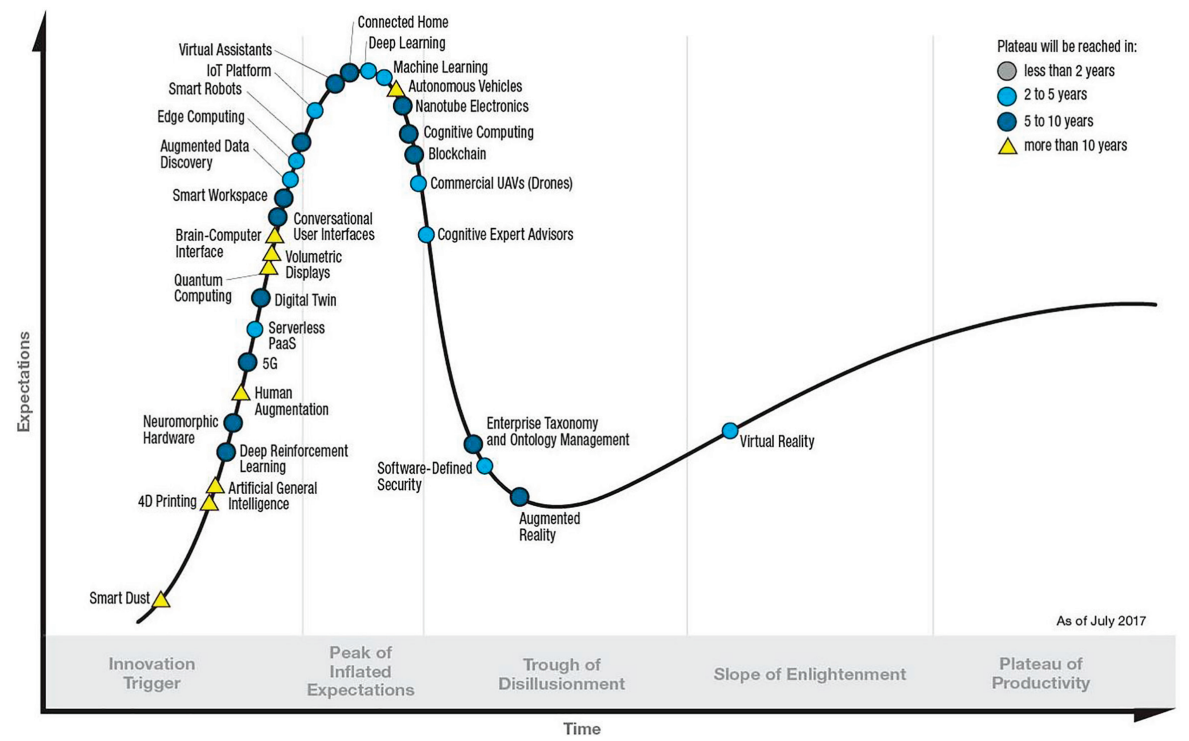

Source(s): authors' elaboration 
Summing up, the user can buy Trust Tokens on an exchange marketplace or directly on the platform to operate on it, the Beneficiary Tokens will be sent to the beneficiaries' accounts according to the settlor's wishes, while the Property Tokens will be distributed to users who buy shares of the conferred properties through Trust Tokens in proportion to their shares.

This is enabled by a marketplace on the platform in which it is possible to buy and sell Trust Tokens or buy, sell or rent a property conferred into the Smart Trust.

Buying and selling. The assets conferred in the Trust must be managed by the platform according to the Settlor's guidelines included in the smart contract in order to guarantee the satisfaction of the beneficiaries' needs. For this purpose, it may be necessary to rent or sell the conferred real estate properties to potential lessees and buyers.

The platform provides a brokerage service to search for buyers and tenants for the assets conferred in the Trust.

Sales of assets. If the will to sell the property conferred upon the occurrence of certain conditions is included in the clauses imposed by the settlor, it is necessary that the Smart Trust is set in such a way as to ensure the transfer of ownership of the property to the new owner once the transaction is completed.

The buyer will be able to check and analyze the properties offered on the platform through a section in which the assets conferred in the Trust put up for sale will be displayed. Once the property has been selected, the buyer will be able to select the desired number of shares according to the availability and the price and make the purchase by paying with Trust Tokens. The Trust Tokens used for the purchase will be distributed to the beneficiaries of the assets conferred in the Trust in proportion to the quantity of Beneficiary Tokens held.

Once purchased, the property or part of the property, the buyer will receive a quantity of Property Tokens proportional to the shares of the property purchased, which certify the ownership and which can be converted into Trust Tokens and consequently into Euro in the marketplace integrated in the platform.

If there are more than one buyer for a given property, the platform provides a management system of the property itself based on the approval of propositional solutions through a vote proportional to the Property Tokens owned by the various buyers.

In this way, the Smart Trust allows the purchase and sale agreement to be concluded with the transfer of ownership of the asset or part of it to the buyers and the payment of revenues to the beneficiaries of the Trust, as well as the future management of the shared property (see Figure 12).

Rent of assets. If the settlor intends to lease the property assigned to the Trust, the platform must be set up to guarantee a secure and transparent transfer of money for the payment of the rent to the beneficiaries from the tenant.

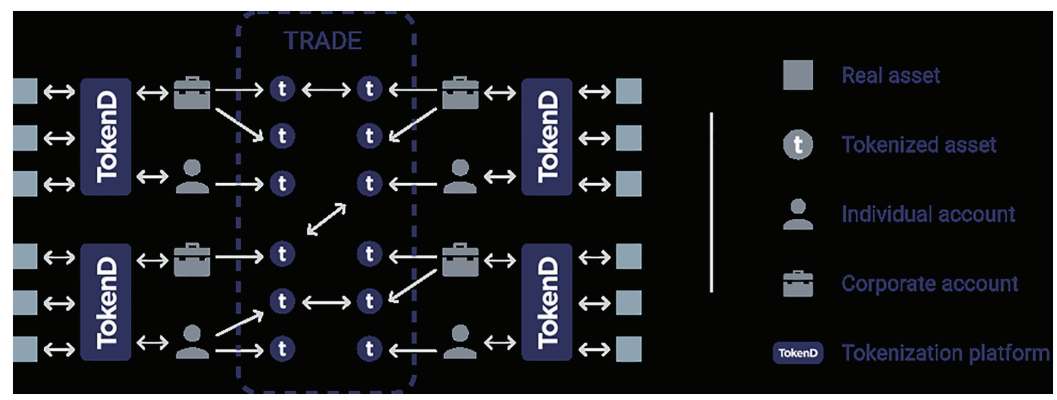

Source(s): authors' elaboration

Blockchain and real estate

289
Figure 12.

Process flow of the purchase/sale of the tokenized assets 
As in the previous case, the user will be able to analyze the offer of rental properties among the assets conferred in the Trust and select the most suitable according to their needs. Once the property has been selected, the user must send a request to the owner who will be able to accept or refuse, based on the proposed offer and the verification of the user's credentials.

In case of positive outcome, the smart contract on which the Smart Trust is based will start the procedure for creating a temporary lease contract, allowing the lessee to use the asset for the selected period and in the established economic conditions.

The lessee will pay the lease monthly using Trust Tokens, which will be distributed to the beneficiaries of the asset in proportion to the amount of Beneficiary Tokens held.

The use of the Internet of Things (IoT) could generate additional services that could smartly manage some processes, starting from the simple access to the rented property through an electronic key that allows entry for the established period and after checking the regular payment of the rent.

In case of both sale and leasing, the platform provides an escrow service managed through the smart contract incorporated in the Smart Trust, which holds the Trust Tokens used for the payment of the shares or the rental of properties until the transfer of ownership or the use of the leased property will be authorized (see Figure 13).

Adjustment for "Dopo di Noi" (After Us): DDN utility token. Once the objectives and methods of intervention of the Dopo di Noi (After Us) project have been defined, we have considered the possibility of implementing and adapting the second solution's platform, designed for the management of the Trust instrument, to this project, in order to propose an application to a real case study. Indeed, examples of application of blockchain technology may include service costs, real estate as a service, building maintenance, settlements of various forms of taxation (Veuger, 2018).

The protection of the disabled person is the main goal of the Dopo di Noi project, and in particular the Trust instrument plays a key role in the management of the property assets owned or used by disabled persons. The substantial difference with respect to the use of the Trust for the benefit of a subject not suffering from severe disabilities lies in the fact that, in the Dopo di Noi project, the priority is given to the management not only from a purely economic point of view but also from the perspective of the protection of the vulnerable persons. Indeed, the basic clauses of the contract are focused on satisfying the needs and wellbeing of the disabled persons, and the real estate assets conferred are mainly used for the support of persons with disabilities, even of those who are not part of the family of the property owners who decided to set up the Trust.

This aspect is very important from the point of view of sharing and mutual help that the project itself wants to encourage; indeed, by promoting concessions for the establishment of Trusts in favor of disabled persons, sharing economy by private individuals who make their real estate assets available as temporary or permanent donations is facilitated.

The platform that offers a solution for the management of the Trusts related to the Dopo di Noi project has the same characteristics and functioning of the standard platform, but it has some peculiar features in order to focus on the needs of the beneficiaries and the relative services.

The peculiarity consists in the fact that the settlor that confers the assets in favor of the disabled person, whether it is an institution, a private person, a parent or the disabled persons themselves, has the possibility to tokenize such properties and sell their shares. In this case, however, buyers purchase the shares of the property using the DDN Utility Token, which can be purchased on the platform, and the beneficiaries of the Trust can use it to pay for the provision of numerous services for their personal care through companies affiliated with the platform itself (see Figure 14). 


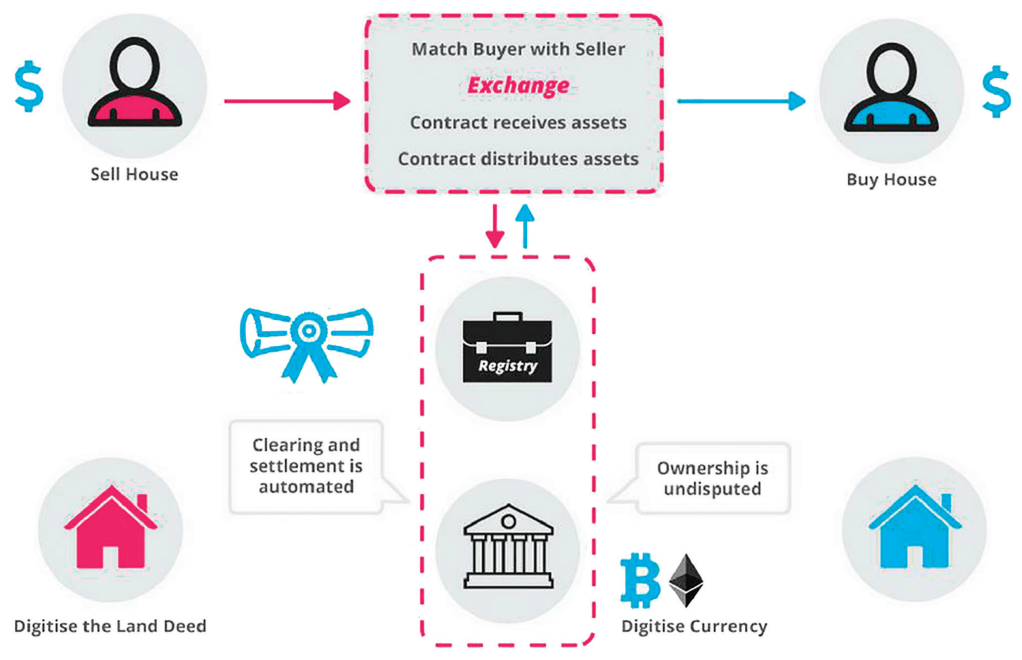

Blockchain and
real estate

291

Source(s): authors' elaboration

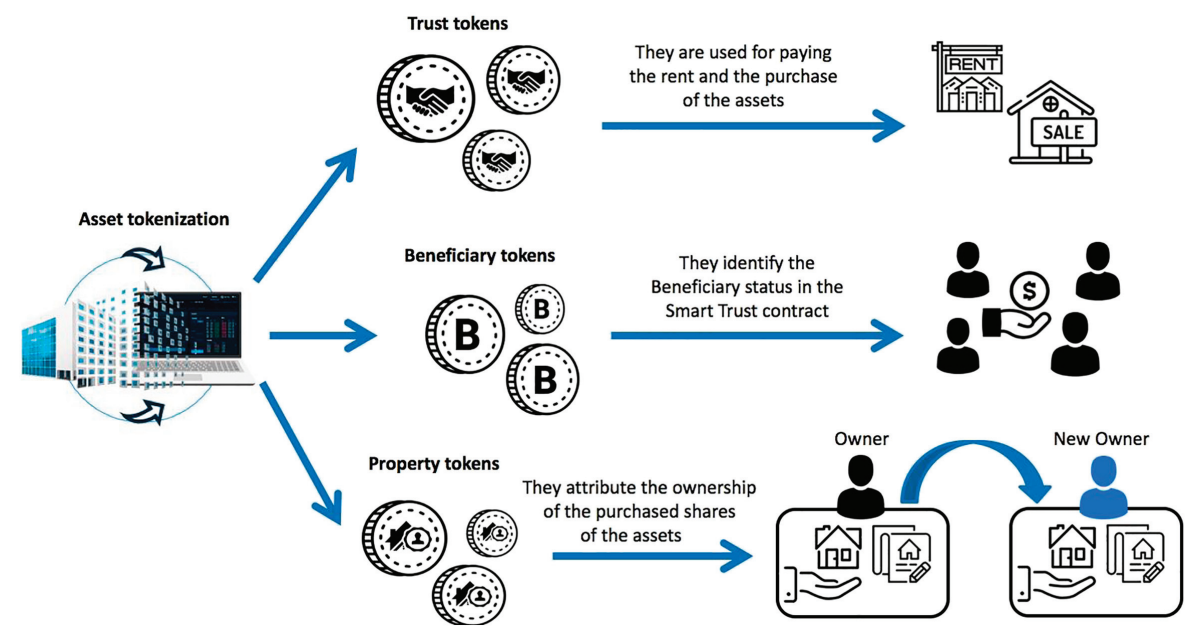

Source(s): authors' elaboration

\section{Comparison between the two solutions}

The two solutions present different complexity and applicability in the real world, taking into account potentiality and criticality of the technology in order to propose one concrete and useable platform and another slightly utopian platform applicable perhaps in not too far a future.

The first simpler solution is based on timestamping application: a digital seal to all the offchain documentation, which makes immutable the Trust's deed and the documents related to 
the activity of the trustee. In this case the scheme is still supported by off-chain natural language contracts (see Table I).

In the second, more complex solution, off-chain contracts are transformed by code language into "smart contracts," which are able to automatically perform certain actions on the blockchain when a given condition is met. Clearly it is arduous to foresee every possible future scenario, even though this solution can include some external agents, the Oracles, which can set off some actions when the occurrence of a certain condition takes place. Furthermore, the platform could also make it possible the purchase of services needed by the disabled person through the use of tokens, which have properties in the Trust as underlying asset. Technical, social and legal constraints make this solution quite futuristic. For the moment a completely decentralized solution is not feasible, having to fall back on a hybrid solution that combines some aspects of the technological innovation with those of the traditional system. In the end the two solutions are not to be considered alternative, but complementary having a different level of implementation (Table II).

\begin{tabular}{lr}
\hline Region & Amount (Euro) \\
\hline Abruzzo & $1,980,000.00$ \\
Basilicata & $900,000.00$ \\
Calabria & $3,060,000.00$ \\
Campania & $9,090,000.00$ \\
Emilia Romagna & $6,570,000.00$ \\
Friuli Venezia Giulia & $1,800,000.00$ \\
Lazio & $9,090,000.00$ \\
Liguria & $2,250,000.00$ \\
Lombardia & $15,030,000.00$ \\
Marche & $2,340,000.00$ \\
Molise & $450,000.00$ \\
Piemonte & $6,480,000.00$ \\
Puglia & $6,210,000.00$ \\
Sardegna & $2,610,000.00$ \\
Sicilia & $7,740,000.00$ \\
Toscana & $5,490,000.00$ \\
Umbria & $1,350,000.00$ \\
Valle d'Aosta & $180,000.00$ \\
Veneto & $7,380,000.00$
\end{tabular}

Table I.

Regional resources allocation[4]

\section{First solution}

\section{Simpler}

Mix of current and innovative process (off-chain documents and timestamping)

Table II.

Comparison between the two solutions. Source: authors' elaboration

Feasible

\section{Second solution}

More complex

Transformation of information and clauses of the Trust act into code language: use of automated process (smart contract and smart property)

No intermediaries other than Oracles (link between real world and blockchain environment)

Tokenization of assets: possibility to sell/rent properties and buy services through tokens Today's technical, social and legal constraints make the implementation futuristic 


\section{Conclusion}

The paper proposes two potential solutions for managing the Trust legal tool in the real estate sector, specifically within the framework of Dopo di Noi project. This project allows, among other features, legal and tax facilitation for the institution of Trusts to benefit persons with severe disabilities.

The first simpler proposal is based on timestamping application.

The second one radically changes the classical Trust model and introduces an automated level in the process: a platform that gathers, in a single network, various elements of the blockchain technology, such as smart property, smart contract, and links them in order to provide services to persons with severe disabilities.

The implementation of the blockchain technology for real estate property transfers allows to leverage the auditability for external stakeholders, lower bureaucracy time and costs, enhance settlement processes, improve transparency, accuracy and security of the real estate system thanks to permanent and public recorded property transactions.

Among these features, immutability, transparency and security of the system stand out, but the greatest potentiality is represented by decentralization.

Beyond positive aspects, critical aspects must be pointed out such as the difficult transition from a traditional structure to a decentralized one and the delay of the regulatory adjustment toward technological innovation. As highlighted by Peter Yeoh (2017), "Blockchain-widening applications could continue to require thoughtful employment of existing legal frameworks combined with new legal solutions. This poses the adaptability challenge for legal frameworks."

Furthermore, these technologies still have to face some challenges "to be ready for mainstream business adoption without increasing the risk to businesses and society's wellbeing due to design or

Implementation vulnerabilities and potential cyberattacks that may exploit those vulnerabilities" (Conte de Leon et al., 2017).

Finally, another important challenge for applications in the real estate sector is standardization of documents (e.g. contracts, reports, etc.): currently only "original" files can be stored and shared; standardization could allow the automated validation of information (Wouda and Opdenakker, 2019).

So, due to the technical, social and legal constraints, nowadays a completely decentralized solution characterized by the disintermediation and elimination of the third parties is not possible; human off-chain interventions and a series of compromises are still required.

Actually, also the second solution proposed is not completely decentralized; third parties operating outside the blockchain such as the Oracles are introduced.

In addition, the decentralization is made extremely difficult by the fact that is almost impossible to anticipate any possible development over time. Indeed, in case of disputes or unexpected events in the traditional trust structure, the problem can be solved through the decision of a judge, an off-chain human intervention. Unless there is future development in the artificial intelligence field, it is really hard to provide a smart contract whose clauses can handle every kind of situation.

The first proposal could be a feasible solution: a hybrid approach that combines some aspects of the technological innovation with those of the traditional system, providing significant benefits in terms of transparency and security.

\section{Notes}

1. IoT (Internet of Things), a term invented by the MIT researcher Kevin Ashton to indicate the set of real objects connected to Internet (Casali, 2017).
Blockchain and real estate 
2. https://chainpoint.org/ (accessed 21 May 2019).

3. https://distributedlab.com/ (accessed 21 May 2019).

4. Anfass, "Analisi con domande e risposte sulla Legge n. 112/2016 e Linee Guida per la sua attuazione" available at: http://www.anffas.net/dld/files/ANALISI $\% 20 \mathrm{CON} \% 20 \mathrm{DOMANDE} \% 20 \mathrm{E} \% 20 \mathrm{RISPOS}$ TE \% 20SULLA \%20LEGGE \%20N_\%20112\%20DEL \% 202016\%20E\%20LINEE\%20GUIDA \%20 PER \%20LA \%20SUA \%20ATTUAZ̄IONE \% 20\%20A \%20CURA\%20DI \%20ANFFAS\%20ONLUS(1). pdf (accessed 07 May 2019).

5. “OpenTimestamps", available at: https://opentimestamps.org (accessed 07 May 2019).

\section{References}

Arsenault, C. (2016), Property Rights for World's Poor Could Unlock Trillions in 'dead Capital': Economist, The Thomson Reuters Foundation, 1 August, available at: https://www.reuters.com/ article/us-global-landrights-desoto/property-rights-for-worlds-poor-could-unlock-trillions-in-deadcapital-economist-idUSKCN10C1C1 (accessed November 2017).

Casali, A. (2017), "IoT e Blockchain, il binomio alla base della digital transformation", Blockchain4innovation, 29 January, availabsle at: http://www.blockchain4innovation.it/iot/iote-blockchain-il-binomio-alla-base-della-digital-transformation/ (accessed 07 May 2019).

Conte de Leon, D., Stalick, A.Q., Jillepalli, A.A., Haney, M.A. and Sheldon, F.T. (2017), "Blockchain: properties and misconceptions", Asia Pacific Journal of Innovation and Entrepreneurship, Vol. 11 No. 3, pp. 286-300.

Deloitte (2018), "Blockchain and smart contracts could transform property transactions", The Wall Street Journal, 3 January, available at: http://deloitte.wsj.com/cfo/2018/01/03/blockchain-andsmart-contracts-could-transform-property-transactions/ (accessed 07 May 2019).

Ferrari, R. (2017), “Tutte le caratteristiche, le evoluzioni e le potenzialità del sistema Blockchain”, ninja, 17 February, available at: http://www.ninjamarketing.it/2017/02/17/caratteristiche-evoluzionipotenzialita-blockchain-roberto-ferrari-chebanca/ (accessed November 2017).

Fuller, A. (2017), "How the blockchain is revolutionizing the money transfer industry", Finder, 24 September, available at: https://www.finder.com/international-money-transfers/blockchain (accessed November 2017).

Kravchenko, P. (2017), “Assets will Be tokens (and it will change finance)", Coindesk, 13 November, available at: https://www.coindesk.com/tokenization-will-make-assets-more-valuable/ (accessed 07 May 2019).

Lemieux, V.L. (2016), “Trusting records: is Blockchain technology the answer?", Records Management Journal, Vol. 26 No. 2, pp. 110-139.

Liu, S. (2018), "Everything you need to know about blockchain and real estate", 22 January, available at: https://www.propertyme.com.au/blog/industry-news/blockchain-real-estate (accessed 07 May 2019).

McKeon, S. (2017), "Traditional asset tokenization", hackernoon, 11 August, available at: https:// hackernoon.com/traditional-asset-tokenization-b8a59585a7e0 (accessed 07 May 2019).

Nakamoto, S. (2018), "Bitcoin: a peer-to-peer electronic cash system", available at: https://bitcoin.org/ bitcoin.pdf (accessed 27 May 2019).

Nawari, N.O. and Ravindran, S. (2019), "Blockchain and the built environment: potentials and limitations", Journal of Building Engineering, Vol. 25, 100832.

Panetta, K. (2017), “Top trends in the gartner hype Cycle for emerging technologies, 2017”, smarter with gartner, 15 August, available at: https://www.gartner.com/smarterwithgartner/top-trendsin-the-gartner-hype-cycle-for-emerging-technologies-2017/ (accessed November 2017).

Regione Lombardia (2017), "Dalla legge 112/2016 disposizioni sul «Dopo di Noi» al programma operativo di regione lombardia approvato con dgr 7 giugno 2017, N. 6674”, 7 June, available at: 
http://www.regione.lombardia.it/wps/wcm/connect/3993d57f-90c8-4173-83c1-582fe247e294/DOP O+DI+NOI_slide.pdf?MOD=AJPERES\&CACHEID=3993d57f-90c8-4173-83c1-582fe247e294 (accessed 07 May 2019).

Santander InnoVentures, Olyver Wyman and Anthemis group (2015), "The Fintech 2.0 Paper: rebooting financial services", available at: http://santanderinnoventures.com/wp-content/ uploads/2015/06/The-Fintech-2-0-Paper.pdf (accessed November 2017).

Todd, P. (2016), "OpenTimestamps: scalable, trust-minimized, distributed timestamping with Bitcoin”, 15 september, available at: https://petertodd.org/2016/opentimestamps-announcement (accessed November 2017).

UK Government Chief Scientific Adviser (2016), "Distributed ledger technology: beyond block chain”, available at: https:/www.gov.uk/government/uploads/system/uploads/attachment_data/file/ 492972/gs-16-1-distributed-ledger-technology.pdf (accessed November 2017).

United Nations (UN) (2006), "Convention on the rights of persons with disabilities", available at: https:/www.un.org/development/desa/disabilities/convention-on-the-rights-of-persons-withdisabilities.html (accessed 27 May 2019).

Vaughan, W., Wilkinson, S. and Bukowski, J. (2015), “Chainpoint”, 22 July, available at: https://www. weusecoins.com/assets/pdf/library/Chainpoint\%20Whitepaper.pdf (accessed 7 May 2019).

Veuger, J. (2018), "Trust in a viable real estate economy with disruption and blockchain", Facilities, Vol. 36 Nos 1/2, pp. 103-120.

Vidal, M.T. (2017), "Tokenizing real estate on the blockchain”, medium, 27 July, available at: https:// medium.com/@mariat.vidal/tokenizing-real-estate-on-the-blockchain-9a13ae99bf11 (accessed 7 May 2019).

Wolfson, R. (2017), "The future of investing: tokenizing traditional assets on the blockchain", HuffPost, 17 November, available at: https:/www.huffingtonpost.com/entry/the-future-ofinvesting-tokenizing-traditional-assets_us_5a0f4aaee4b023121e0e927d (accessed 7 May 2019).

World Economic Forum (2015), "Deep shift. Technology tipping points and societal impact. Survey report, September 2015", available at: http://www3.weforum.org/docs/WEF_GAC15_ Technological_Tipping_Points_report_2015.pdf (accessed November 2017).

Wouda, H.P. and Opdenakker, R. (2019), "Blockchain technology in commercial real estate transactions”, Journal of Property Investment and Finance, Vol. 37 No. 6, pp. 570-579.

Yeoh, P. (2017), "Regulatory issues in blockchain technology", Journal of Financial Regulation and Compliance, Vol. 25 No. 2, pp. 196-208.

Zaccaria, R., Ferri, G. and Pavesi, A. (2018), Cambiare l'abitare cooperando. Il gestore sociale cooperativo infrastruttura dell'housing sociale e del welfare urbano, Mondadori, Milano.

\section{Corresponding author}

Marzia Morena can be contacted at: marzia.morena@polimi.it

For instructions on how to order reprints of this article, please visit our website:

www.emeraldgrouppublishing.com/licensing/reprints.htm

Or contact us for further details: permissions@emeraldinsight.com 